Journal of the American Medical Association.

EDITED FOR THE ASSOCIATION BY N. S. DAVIS.

PUBLISHED WEEKLY.

Vol. VII. ChICAGo, OCTO
ORIGINAL ARTICLES.
HEALTH INSURANCE, OR OUR FINANCIAL RELA-
TION TO THE PUBLIC.

BY WOODS HUTCHINSON, A.M,. M.D.,

JHCTURIR UN HYGIENE, JOWA COLLEGR OF PHYSICIANS AND SURGHONS, DBs MOINBS, IOWA.

If $I$ were to put the question to this august representative assembly, "What is the most annoying and unpleasant feature of our professional work, from what source spring our most harassing, though comparatively petty cares and our most provoking disappointments?" I think I should have no difficulty in determining even if all spoke at once, that what we may call the financial question in medicine, enjoyed that "bad eminence" more generally than any other which could be suggested. No doubt much of this difficulty and unpleasantness is inherent in the very nature of the process; for this is the point of metamorphosis at which our talent and industry must be coined into their equivalent of hard cash, where our lofty ambitions, noble aims or Utopian schemes for benefiting the race, come into merciless contact with the hard, cold realities of life and the struggle for existence, always at best a mortifying experience. Friction at this point is inevitable, a reduction to a minimum is all we can hope to effect. Whether the financial relations which we sustain to the laity are the best possible which could be assumed to effect this reduction, is the question to which I wish briefly to call your attention to-day. I stand here simply as an animated interrogation point.

No doubt the question has suggested itself to many of you that the treatment of this subject would have been much more appropriately undertaken by one of wider experience and longer standing in the profession, but it is the peculiar privilege of youth and inexperience to ask the raison d'etre' even of truths which we have come to regard as axiomatic and customs which have grown hoary with centuries of observance. Is the system of remuneration only for services rendered, in fact of making a physician's income from a family or community depend solely upon the amount of sickness occurring in it, the best that can be devised for the mutual interests of both parties concerned? Such practically is our system. Its philosophy might be condensed in the motto "Millions for Cure, but not one cent for Prevention."

${ }^{1}$ Read in the Section on Public Henlth at the 'Thirty-Seventh $\Lambda$ nnual Mecting of the American Medical Associntion.

The astute Chinese who were discussing civil service reform when our ancestors were building the reec hut and hurling the flint-tipped javelin, are said to pay their medical attendants regularly as long as they enjoy good health, but to promptly discontinue their remittances on the first appearance of sickness, to resume only on recovery; which no doubt has arisen from their absurdly attempting to live up to a foolish old proverb of ours about " an ounce of prevention."

It seems to me that the weakness of our system lies in this one fact, that it gives us such an exceedingly limited opportunity for what has been well called the practice of preventive medicine. No one thinks of consulting us until they at least "feel unwell," and in many instances not until days, or even weeks of precious time have been wasted or worse, in trying to "wear the trouble off," or in blindly applying every crude remedy which household experience, patent quackery or superstition can suggest; all because they are "not sick enough to call a doctor" in other words don't feel uncomfortable enough to be willing to pay more than the price of a bottle of patent medicine for relief. 'To such an extent has this habit of delaying been carried, that we often find patients hesitating to call us in just because they are unwilling to admit even to themselves that they are "so seriously ill" as to need our services. In fact the abominable phrase "sick enough to need a doctor" has become almost the popular synonym for, at best, a serious indisposition and often a well developed stage of a possibly fatal clisease. 'The phrase and the feeling that it represents ought to be obliterated from the speech and thought of every civilized community. Through its influence, we are brought face to face with the legitimate result of months or even years of violation of the laws of our being aggravated by days of neglect or maltreatment, and confidently expected to avert the vengeance of outraged nature and undo the work of years, in days or weeks. "If I had only been called sooner" is a sadly familiar phrase in our professional vocabulary. 'To thus stem or even reverse the current of nature, we are driven to use the most powerful agents, many of them deadly poisons, to call " halt!" in tones which will compel the attention of the most obstinate morbid process and every few decades, a not wholly unnatural wave of popular indignation sweeps over the community, not against itself for living so as to render such drugs indispensable, but against physicians, forsooth, for prescribing them. It was on the crest of such ever recurring waves that the Hahnemanian, Thompsonian, Botan- 
ical, Hydrojathic and Faith cure manias successively came into popular favor. Thus the mutual confidence and sympathy which should exist between the profession, and the public is seriously impaired and the interests of both suffer in consequence. Would not a system of constant medical attendance, remunerated alike in sickness and in health, enabling us to give advice or treatment just when we see it is needed, even if unasked, and renciering professional counsel, not only in disease but in health, the first thought, the easiest and most natural thing, the rule instead of the exception; would not such a scheme as this, if practicable, most happily modify the condition of affairs and prove a long step toward securing the health and happiness of the race?

l3ut supposing ourselves installed in full charge of a case, are we even then freed from the perplexities of our financial system? Scarcely even then. How often are we annoyed in the very midst of a serious case, when every shadow of change must be instantly noted and promptly met, by the remark of the family, friends, or even of the patient, that they "can't afford to have us come so often." This fortunately is not a very common experience, but all of us can testify that when it does occur it is, to say the least, exceedingly disheartening. When, however, we reach the period of convalescence, another head of the hydra springs up to confront us: "Really, doc. tor, I feel so much better this morning that I don't think you need call again until I send for you," is the remark of our wan-lipped and languid patient, blissfully ignorant of the hundred and one pitfalls which yet lie between him and health, and we can but submit to his decision or run the risk of being thought anxious to make all we can out of the case and possibly of having our bill for subsequent services protested. How often are we called in hot haste only to find our patient beyond help, or if we escape this, how frequently does the convalescent, dissatisfied with the slow and uncertain progress he is making, conclude with charming consistency that it is the fault of our treatment, "too much strong medicine" perhaps, and resort to some rival physician, quack or vender of patent medicines, to whom he ascribes all the credit of the cure. These results are patent to the most unskilled eye, but what a prophecy of evil to come, can be read in living letters by the eye of the trained observer in the history of many of these half cured cases even when their course and termination may have been perfectly satisfactory to the unsuspecting patient and his friends. How many of our mdst serious and most obstinate chronic troubles spring directly from the half removed result of some acute attack? How often are the germs of evils which will curse generations yet unborn, left lurking in the system, simply because the subject thinks him. self cured and doesn't want to make his bill any larger? Of course much of this too early cessation of treatment is due to a simple aversion to taking any kind of trouble unless spurred on by pain or fear, but would not this tendency be greatly checked by a knowledge on the patient's part that his bill at the end of the year would be just the same whether he took further treatment or not, while other advice or new remedies would be an additional expense; as would be the case under a system of constant attendance.

What influence does our present system of attendance give us over the sanitary surroundings, diet or habits of life of our patients? Almost none. It is true we have the priceless privilege of giving any amount of excellent advice on these subjects, which they may perhaps remember for a week, though usu. ally they regard it simply as customary and harmless prelude to the prescription which they regard as the "value received" for their fee. Such an effect has the proportioning of our remuneration to the number of distinct definite services rendered had upon the ideas of the laity, that many of them have no idea of paying for anything, except some such tangible benefit as a prescription or an operation. In some instances we are actually obliged to give a prescription in order to secure the right (in their minds) to claim a fee. They will pay a dollar for a prescription and get the advice thrown in for nothing, and as the immortal "Josh Billings" has sagely remarked, "what people gets for nothing they are mighty apt to value at about what they gave for it." Over the home life of our patients, we have almost no control or even supervision until after the mischief (which often might have been averted by a few timely precautions) has been done, and even that ceases almost as soon as we began to exercise it. What sort of success would we expect from a nurseryman who was not permitted to prune his trees until they were already misshapen, to destroy their infesting parasites until the foliage was withered, who was not allowed to water them till they began to droop or manure them till they were almost exhansted? And yet this is the relation to the bodies of our patients in which we are practically placed by our present system. The words "cobbler and tinker" are terms of reproach, and yet cobbling and tinkering is about all we are permitted to do to the vital mechanisms of most of our patrons.

When we consider this fact in the light of the deliberate statement of $\mathrm{Mr}$. Chadwick, the distinguished linglish sanitarian, that he can build a city which shall have any required death-rate from 3 per 1000 up. When we remember that "the white plague of the North," as Holmes aptly calls consumption which is responsible for the lion's share of our death-rate, is more than analogous to the familiar spindling of plants deprived of air and sunlight; that as much as fifty years ago, even a layman like Lord Palmerston declared that "for every death from typhoid somebody ought to bang;" that an unfailing specific for malaria, diphtheria and cholera, is contained in a six inch drain tile, in short that nearly one-half of our existing diseases are absolutely preventable, does not a readjustment of our relation to the public appear urgently necessary? How would a system of constant attendance at a fixed sum per year or month, including an annual or semi-annual sanitary inspection of the residence and surroundings, and review of the diet and habits of life of the family, if practicable, modify the conditions under which we are now attempting to promote the health of the public? I 
am well aware that this system at present is generally stigmatized by us as a "quack method" if not a form of quackery itself, but I think even the bad hands into which it has to some extent fallen, should not prevent our candidly recognizing, and, if worthy, appropriating any feature of value which it may possess. Besides, we must remember that the system in part at least, is in practical operation in the different lodges and benefit associations, in manufacturing establishments and mines all over the country, with generally eminently satisfactory results regarded from an economic standpoint. Of course the principle upon which all these plans are adopted is a purely economical one, to get the greatest amount of service for the least possible cost, and they could only be expected to be a success in this direction.

The plan which I would respectfully submit is much wider in its scope, and is briefly as follows: That at the beginning of the calendar year, each individual or family should engage his or their medical attend. ant for the next twelve months, agreeing to pay him a specified annual salary in advance, either in full or in quarterly or monthly installments. The physician on his part should agree to render any and all professional services required, except operations or manipulations requiring the skill and training of a specialist, for the annual consideration specified, which might readily be fixed according to some rate per capita or per familiam laid down in the fee bill. The physician should further agree in consideration of the sum specified, to make an annual or semi-annual inspection of the sanitary condition of the house and premises of his client, and to offer such suggestions as he saw fit in regard to the diet or habits of life of himself or his family, in short to act as general adviser on all matters of hygiene or therapeutics. The system might briefly, and perhaps not inaptly, be described as a scheme of "health insurance." What are the advantages which seem to be presented by this plan? In the first place, our patients would have no inducement whatever to delay consulting us, in fact moved by a not unnatural desire to get their money's worth out of us, would probably hasten to do so at the earliest appearance of discomfort or danger, and thus give us full control of the case at that period in which a "stitch" properly taken often saves not "nine," but "ninety and nine." We should have every opportunity to abate or favorably modify the attack, and it needs no word from me to point out to you the wellnigh inestimable value of this vantage ground. I,ater during the progress of the case there would be not the slightest danger of any objection to the frequency of our visits, on the contrary the difficulty would lie in exactly the opposite direction, and would constitute the principal drawback of the system. In convalescence, we need fear no interruption to those finishing touches which may exercise such a powerful influence upon the future comfort or safety of our patient, and in the giving of which the master hand finds scope for the finest and most highly appreciated subtleties of its skill.

Above all it would give us a fair opportunity for the practice of the grand branch of preventive medicine, a privilege which under the present system is practically denied to us. How is it that until within the last tew years in scarce even one of our many and justly famous professional schools and colleges, was there to be found a full Professor of hygiene or a chair of preventive medicine? Why is it that one could almost count upon his five fingers all the really valuable and exhanstive treatises upon this subject by American authors? Where are the Grosses, the Bartholows, the Flints, the limmets of $\mathrm{H}$ ygiene or the Agnews, the Hammonds, the Knapps and the Roosas of Preventive Medicine? 'The profession of the United States has yet to produce the man who has won a national reputation solely by his work or writings in this department. One reason at least for this state of affairs is not far to seek; the field for work in this direction has been either so exceedingly limited or so barren and difficult of cultivation as to almost deprive us of any inducement to develop it. Skill and proficiency in any other branch of our art are highly ap. preciated and well remunerated, but in this one they are regarded with the utmost indifference. As medical students we are required to practically acquaint ourselves with, say seven branches in a comparatively short space of time, knowing that the public are quite willing to pay us for proficiency in six branches out of the seven, but will hardly even accept our advice gratis in the seventh, and the result is well-nigh inevitable. How can we expect it to be otherwise when the student has absolutely no prospect of a fair remuneration for the time and labor expended in obtaining a thorough knowledge of this branch, unless he chooses to enter the uncertain arena of politics as a candidate for the often poorly paid and unpopular position of a health officer? In spite of this utter lack of pecuniary or even honorary inducement, in the face of sneers at his "pretended" zeal, to his everlasting credit be it spoken, the American physician is today the truest promoter of the health of the people, the most earnest, and I had almost said, the only persistent advocate of sanitary measures; but would not the "health insurance" system if generally adopted give a new dignity to his labors and immensely increase the scope of his energies?

Would not this system also do much to break up that unfortunate mental habit impressed upon us from earliest infancy which involuntarily connects the doctor with discomfort and bitter medicine, if not with the undertaker and the sexton? A habit whose influence upon the popularity of the profession, though slight, is sometimes unpleasantly appreciable. It would also tend to lessen the present unfortunately too common tendency to select professional advisers on the spur of the moment or dismiss them from some momentary impulse of dissatisfaction, a course highly prejudicial to the interests of both parties. Most men give less careful, deliberate consideration to the choice or dismissal of their family physician than they would to the consummation of a horse-trade. The financial advantages of the scheme in rendering our incomes, not only more definite, but also more certain, are obvious, and the few figures bearing upon the subject which I have been able to collect, which I dare hardly dignify by the name of statistics; render it at least highly probable, that a rate per annum can 
be fixed, which would be both satisfactory to the public and remunerative to us. The agreement would simply be an ordinary common sense business arrangement, legally binding, so that there could be no possible objection on the part of our clients to being reminded of their delinquencies by a collector or any dissatisfaction with the size of the bill. Each "policy holder" would know in advance the exact amount of his "premium" and the date at which it would be due, and could prepare to meet it promptly like any other business obligation, instead of, as now, neither knowing the amount nor the date till after it is due and regarding the obligation as a part of an inscrutable dispensation of Provikence, which he will try to meet when he can conveniently spare the money.

Now just a word on the drawbacks of the scheme, though it is probably a subject which might safely be left to those who are to follow me. No doubt the oljection which is already uppermost in the minds of most of you is the enormous and unreasonable demands on our time, which would be made by some of our patients under this system. In addition to the insane craving of some persons for constant medical attendance. there will be added the not wholly unnatural desire to "get their money's worth" out of us, but would we not be in some respects, in a better position to meet these demands than at present? In the first place, when entering upon the agreement, we should give our patients to clearly understand that they were engaging us, not to be simply medicinecarriers or visit-makers, but to advise them to the very best of our judgment, and that the question of the necessity of the visit must be left largely to our discretion. Then the tenure of our professional position being so much more secure, we shall be able to treat these unreasonable cases on a much more rational basis. We could safely reason with them, if necessary reprove or scold them, or even occasionally afford to tell them the truth. We might occasionally find ourselves in a position to make use of Abernethy's celebrated prescription given to a gentleman who somewhat pompously introduced himself as "James Peet, of Rock Villa, Clonmel, Waterford, Ireland." It was not committed to writing, but was delivered verbally somewhat as follows: "James Peet, of Rock Villa, Clonmel, Waterford, Ireland, go back to Rock Villa, Clonmel, Waterford, Ireland, and fancy you are well and you will be well." If these means should fail us, there are a hundred and one rusty weapons in our armamentarium such as blisters, nauseous draughts, venesections, or hypodermatic injections of aqua destillata, which could be used with deadly effect.

lut perhaps the most practical objection would be based on the probable unwillingness of the laity to pay any sum in advance for services which they are not even sure that they are going to need; but even this objection loses some of its force, when we consider the almost innumerable number of lodges, guilds and benefit associations into which not only the educated, but even the most unintelligent classes are forming themselves for just this kind of mutual protection. When we further consider that scarcely fifty years ago, life insurance was regarded as not only absurd and impracticable, but even impious, while now men of every condition are willingly paying from $\$$ to to $\$ 1000$ a year solely for life insurance, it would scarcely seem improbable that their education up to the point of paying the comparatively trifling sum necessary for "health insurance" would simply be a matter of months or years.

Of course the annual fee would necessarily have an important effect on the weight of this objection. This can only be determined by past experience. Simply as a rough estimate of the probable amount of this fee, I would refer to a few fragmentary statistic which I have been able to collect. These statistics have been taken from four different ledgers, one of which was kept in a country village of about I 200 inhabitants, another in a town of about 6000 inhabitants, and the other two a city of 35,000 population, thus embracing nearly all classes of practice. The results even from so small a number of data are comparatively uniform. The village series comprises only twenty-seven families, or about 130 persons, who spent the exceedingly low sum of $\$ 7$ per annum for medical attendance. The town statistics, covering nearly 400 families, show an average of about $\$$ r 3.50 per annum, while the city series, embracing I 50 families, or nearly 700 persons, show an average expense of over $\$ 19.00 .^{1}$ From these it would appear to be probable that the average expense per annum, making the necessary allowances for healthfulness of location and habits of life, would approximate very closely to $\$ 3$ per annum, or a little over $\$ 1.00$ per month, the actual average from the enclosed figures being $\$$ i 3.60 . When we consider the really appreciable preventative influence which we might exercise, I think we would almost be justified in concluding that we could afford to render the proposed services for the present average expense, or perhaps even for less, especially when we remember the greatly increased certainty of our being paid; and when we can represent to our clients that all these invaluable hygienic advantages may be secured in addition to regular attendance, at the cost of the latter, surely a reasonable man need have no hesitation about adopting the system. Surely we could afford to perform the same services under more favorable circumstances for the same sum. The sum proposed very closely approximates to that contributed by miners for sinilar purposes, the assessments ranging from seventy-five cents a month for a single man, to $\$ 1.25$ to $\$ \mathrm{~J} .50$ a month for a married man, according to the size of his family. Probably a fair average under our system would be for adults $\$ 5.00$ and children $\$ \mathbf{1} .25$ per capita per annum, which would impose almost exactly the average expense per annum on an average family of five members. Taking these scattered figures as an indication, it would hardly appear probable that any serious objection will be raised by the laitv on account of expense. Without doubt the objections to the plan are neither few nor groundless; but are not the advantages proposed to be secured both real and valuable? In fact, it seems to me that the time has already come 1 These statistics cover an average of about three years. 
when an effort must be made to secure them. The crying need of the age is for sound hygienic teaching, and if the profession fail to give it, who can fill their place? I care not what means be adopted to reach the end, but it must be reached, and to provoke a discussion of ways and means is the sole object of these informal suggestions.

Discussion of the paper was opened by $D_{R}$. A LBERT I. Ginon, U. S. N., who stated that while in Nagasaki, Japan, the system suggested was substantially that pursued in his own private practice, and was found satisfactory both to patient and practitioner. It is indeed the only independent and dig. nified way in which to practice medicine.

He was followed by Drs. Horatio R. Storer, of Newport, R. I., W. I.. Schenck, of Osage City, Kan., Geo. H. Rohé, of Baltimore, Md., Foster, of Portland, Me., W.yman, U. S. Marine Hospital, St. Iouis, Hazelwood, of Grand Rapids, Mich., and Tupper, of Michigan, all of whom approved of the plan presented in the main, theoretically, at least; though most of them doubted its practicability at present.

\section{A CASE OF AORTIC ANEURISM TREATED BY THE INSERTION OF WIRE.'}

BV JOSEPH RANSOHOHF, M.D., H.R.C.S.,

PROFRSSOR OI LIRSCRIJ'TIVE ANATOMY AND CIINICAI. SURGHRY, MHDTCAT. Cothisgr ol: onio.

The subject of aneurism never fails to arouse the interest of the surgeon. Happily the progress of our art has been such, that he who is thus afticted needs, as a rule, no longer to consider himself an object of scientific interest solely, but can with at least a fair prospect of successful issue rely upon one or other of the methods recognized as radical in the treatment of his disease. 'There are cases, however, and notably those of the aorta, which are not amenable to ligation or compression, and in which despite medicinal treatment and the observance of absolute rest a rapidly fatal result must be predicted. Such cases ought not to be forsaken without an effort to save. As our science stands to-day, we are restricted to a choice between distal ligation, galvano-princture and the introduction of foreign material into the sac of the aneurisms. It is to this latter method only that I beg to direct the attention of my colleagues of the Surgical Section. The cases of aortic aneurism in which it has been adopted are so few that the report of the following case may prove interesting if not instructive:

Case.-Alfred P., æet. 35, colored, presented himself at the Dispensary of the Medical College of Ohio, and was admitted to the Good Samaritan Hospital in May, $\mathbf{1 8 8 5}$. Has been a moderate drinker, but has always enjoyed good health. Had a chancroid several years ago, but never had syphilis. In August, 1884, while pulling an oar, he made a very sudden and strenuous effort which was followed by a sharp, stinging pain in the right side of the chest.

1 Read in the Section on Surgery at the Thirty-Seventh Annual Meeting of the American Medical Association.
Pain has been constantly present since. Difficult breathing, more or less severe cough and inability to do hard work have gradually supervened. Slight exertions are often followed by paroxysms of dyspnoea that threaten to terminate life. From February 24 to April 27 the patient was an inmate of the Cincinnati Hospital, where, according to the records, he was kept at rest and upon the iodide of potassium, but without marked benefit.

Status prasens.-Man well-nourished and of good muscular development. Breathing labored, short, and frequently interrupted by spells of coughing whereby a thick tenacious mucus is expelled. A marked cedema of the root of the neck and extending to the right side of the face and the shoulder is observed. Inspection of the chest reveals a conical prominence on the right side of the sternum and extending over the second and third intercostal spaces. 'The projection is as large as a fist, pulsates perceptibly, but presents no discoloration of the integument. On palpation a pronounced expansile pulsation is felt from below the clavicle to the fourth rib and from the right margin of the sternum to half an inch beyond the mammary line. The tumor is very soft, fluctuating and exceedingly sensitive to pressure. Percussion elicits a dull sound. No thrill can be felt. Auscultation over the tumor reveals no adventitious sounds produced within it. The cardiac sounds are transmitted with more than ordinary clearness, and particularly is the accentuation of the artic sound noticeable. 'The position of the apex beat is normal. While the paticnt is at rest his pulse is 100 . According to the sphygmographic tracings taken by the late I)r. Keyt, the pulsation in the radials is synchronous and the pulse-waves agree sufficiently in form. Auscultation over the right lung reveals a harsh inspiratory noise below the lower angle of the scapula. Coarse mucous râles are audible over both lungs.

Diagnosis.-Sacculated aneurism of the ascending aorta, with perforation of the chest wall, unattended by atheroma or cardiac hypertrophy.

Treatment. - When the patient was admitted to the Samaritan Hospital he was placed in bed and kept as much at rest as the cough and dyspnoea would. permit. His diet was greatly restricted and 20 grains. of the iodicle of potassium given three times a day. For a week this treatment, with the administration of an hypodermic injection of morphia at night, was continued with apparent benefit. The pain and dyspnoea were somewhat diminished and the pulse rate reduced to 90 per minute. No perceptible change in the aneurism occurred. The improvement in the condition of the patient was dissipated two weeks after his admission after a severe spell of vomiting which was followed by an increase of pain and dyspnosa, and protracted epistaxis. When the irritability of the stomach had been allayed, the administration of the iodide was resumed, but without marked benefit. During the third and fourth weeks of the patient's stay in the hospital, six subcutaneous injections of ergotine were made in the vicinity of the tumor, with but faint hopes of benefiting him. While no direct detriment to the diseased vesse' resulted from 